\title{
Multiparametric magnetic resonance imaging for pre-treatment local staging of prostate cancer: A Cancer Care Ontario clinical practice guideline
}

\author{
Jennifer Salerno, PhD; Antonio Finelli, MD; ${ }^{2}$ Chris Morash, MD; ${ }^{3}$ Scott C. Morgan, MD,; Nicholas Power, MD;4 \\ Nichola Schieda, MD, ${ }^{5}$ Masoom A. Haider, $M D^{6}$
}

'McMaster University, Department of Oncology and Program in Evidence-Based Care, Cancer Care Ontario, Hamilton, ON, Canada; 2Princess Margaret Hospital, Toronto, ON, Canada; ${ }^{3} T h e$ Ottawa Hospital, Ottawa, ON, Canada; ' Western University, London, ON, Canada; ${ }^{5}$ Department of Medical Imaging, The Ottawa Hospital, Ottawa, ON, Canada; ${ }^{6}$ Sunnybrook Health Sciences Centre, University of Toronto, ON, Canada

Cite as: Can Urol Assoc J 2016;10(9-10):E332-9. http://dx.doi.org/10.5489/cuai.3823 Published online 0ctober 13

\section{Abstract}

Introduction: The utility of $\mathrm{T} 2$-weighted magnetic resonance imaging (MRI) in the local staging of prostate cancer is controversial. Due to the success of multiparametric MRI in cancer localization, there is renewed interested in MRI ( \pm functional sequences) for local staging. Guidance on pre-treatment local staging of prostate cancer by MRI was developed using systematic review methodology and expert consultation.

Methods: MEDLINE, EMBASE, Cochrane Database of Systematic Reviews, and other databases were searched to identify studies comparing: (1) MRI staging vs. radical prostatectomy staging on diagnostic accuracy outcomes; and (2) MRI staging vs. routine clinical staging on clinical and patient outcomes. Studies meeting inclusion criteria were synthesized by outcome and sensitivity/ specificity analysis by tumour location was performed. Evidence quality of included studies was assessed and considered in recommendation formulation.

Results: The literature search identified 2510 citations; 62 studies were included. Analysis of MRI $\geq 1.5 \mathrm{~T}$ plus endorectal coil (ER) $( \pm$ functional sequences) in the detection of extraprostatic extension or seminal vesicle invasion showed modest sensitivities $(\geq 50 \%)$ and excellent specificities (>85\%) among patients scheduled for radical prostatectomy. MRI upstaging was shown in 20/21 studies, with large variation in correctness (11-85\%). Scarcity of clinical and patient outcomes among studies limited synthesis and evaluation. Quality assessment found non-trivial biases.

Conclusions: Modest imaging performance was shown for MRI (1.5 $\mathrm{T}+\mathrm{ER}$ and $3 \mathrm{~T} \pm \mathrm{ER}) \pm$ functional sequences in regards to sensitivity. Limitations in study design, reporting of clinical and patient outcomes, and the heterogeneous use of MRI tempered the strength of the recommendations.

\section{Introduction}

Prostate cancer among men in Canada ranks first in terms of the number of new cases $(21.6 \%)$ and third in terms of mortality $(9.9 \%)$, after colorectal cancer $(11.8 \%)$ and lung cancer $(25.3 \%){ }^{1}$

Prostate cancer is typically diagnosed through a combination of prostate-specific antigen (PSA) screening, digital rectal examination (DRE), and transrectal ultrasonography (TRUS)-guided biopsy. Limitations when locally staging prostate cancer for treatment planning purposes include: low specificity, missed regions of the prostate during DRE or biopsy (e.g., anterior tumours), and potentially inaccurate information regarding tumour volume, extent and aggressiveness of disease with DRE and non-targeted TRUS-guided biopsy. ${ }^{2}$

There is renewed interest in the benefits of magnetic resonance imaging (MRI) ( \pm functional sequences) in the local staging of prostate cancer. T2-weighted MRI for local staging of prostate cancer traditionally involves high-resolution imaging, which delineates the prostatic anatomy in detail. MRI is non-invasive, can visualize the boundaries of the prostate, and with multiparametric techniques can also determine the location of clinically significant cancers. ${ }^{3}$ Multiparametric MRI (mpMRI) is the addition of two or more functional sequences to MRI, such as diffusion-weighted imaging (DWI), dynamic contrast-enhanced imaging (DCE), and proton magnetic resonance spectroscopic imaging (MRS). The current recommended combination of functional sequences to improve detection and localization of prostate cancer is MRI plus DWI and DCE. This form of mpMRI is gaining wide acceptance and is being adopted for image-guided biopsy, biopsy avoidance, and consideration of image-guided therapy of index tumours; ${ }^{4}$ however, MRI has not gained wide adoption for local staging of prostate cancer, as controversy still exists regarding its value in care and management. 
Recognizing the potential significance of improved cancer localization by MRI and the need to more accurately stage patients compared to conventional methods to aid in radical treatment planning, the Cancer Imaging Program of Cancer Care Ontario (Toronto, Canada) in collaboration with the Prostate Cancer Disease Pathway Management Secretariat developed this clinical practice guideline. An expert group was assembled, including radiologists, radiation oncologists, urologists, and health research methodology as part of the Program in Evidence-Based Care (McMaster University, Canada) to answer the following research questions: what is the performance and diagnostic accuracy of MRI ( \pm functional sequences including DWI, DCE, or MRS) in the pretreatment local staging of prostate cancer and impact on clinical and patient outcomes?

\section{Methods}

A two-staged approach was used: review of existing relevant guidelines and a systematic review. Prior to finalization, the guideline underwent peer-review and stakeholder engagement.

\section{Search strategy}

Potentially relevant guidelines were identified and reviewed by searching online databases and guideline developer websites, and by performing a systematic literature search in standard databases. Search criteria included relevant publications in the last 10 years with clearly described methods and recommendations. MEDLINE, EMBASE, Cochrane Database of Systematic Reviews, and other databases were used to identify primary studies and systematic reviews (Appendix 1).

\section{Study assessment}

Potentially relevant studies were identified and reviewed on the basis of title and abstract by one reviewer (JS). Reference lists were also examined for additional relevant studies. Inclusion criteria were: (1) studies published between January 1, 2008 and February 17, 2016; (2) adults $\geq 18$ years; (3) studies on the pre-treatment local staging of prostate cancer in men with newly diagnosed biopsy-confirmed prostate cancer and candidates for radical treatment; (4) studies of $M R I \geq 1.5 \mathrm{~T} \pm$ endorectal coil $(E R) \pm$ DWI, DCE, MRS; (5) studies with at least one outcome of interest; and (6) minimum size of 30 patients. Studies were excluded if they investigated: (1) technical imaging aspects; (2) post-treatment or pre-diagnosis; (3) other combined technologies; and (4) active surveillance. Studies not in English, case reports, conference abstracts, and in vitro or animal studies were also excluded. There were no exclusions based on study design. Outcomes of interest included diagnostic accuracy (e.g., sensitivity, specificity); clinical outcomes, including stage classification, risk stratification category, treatment plan, surgical margins, and biochemical recurrence; and patient outcomes (e.g., survival). Full-text articles of studies meeting inclusion criteria were retrieved. Potentially eligible systematic reviews were assessed for methodological quality, ${ }^{5}$ with a score $\geq 7$ considered satisfactory. The quality of the evidence was appraised using standardized tools. ${ }^{6-8}$

\section{Analysis}

Data abstraction was performed by one abstractor (JS). Abstracted data included study variables, MRI variables, and outcomes. Scatterplots of sensitivity vs. 1-specificity for studies of MRI $\geq 1.5 \mathrm{~T}+\mathrm{ER} \pm \mathrm{DWI}, \mathrm{DCE}, \mathrm{MRS}$ were examined based on published estimates and stratified by tumour location (i.e., extraprostatic extension [EPE] vs. seminal vesicle invasion [SVI]). MRI studies of $1.5 \mathrm{~T}$ and $3 \mathrm{~T}$ without ER \pm DWI, DCE, MRS were also examined. Median sensitivities and specificities were calculated and interpreted. ${ }^{9}$ Change in stage and change in treatment were calculated from before and after MRI. The percentage of positive surgical margins was stratified by whether or not MRI results were used to inform the nature of radical prostatectomy surgery. Heterogeneity variables included field strength, ER, functional sequences, and sample size. All data were audited by an independent auditor. All analysis included studies of $M R I \pm D W I, D C E, M R S$.

\section{Results}

The literature search identified 2510 citations; 201 papers underwent full-text review. In total, there were 62 included studies (Fig. 1). One systematic review published as a component of a clinical practice guideline ${ }^{10}$ relevant to the objectives, questions, and outcomes of this guideline and with a satisfactory quality score helped to inform the literature search strategy and evidentiary base. Otherwise, a search for preexisting guidelines did not yield an endorsable document. A summary of included primary studies is shown in Table 1.

By outcome, there were 48 primary studies and one systematic review/meta-analysis on diagnostic accuracy; 21 studies on stage classification; two studies on risk stratification; six studies on treatment plan; 19 observational studies and one randomized controlled trial on surgical margins; five studies on biochemical recurrence; and no studies with patient outcomes.

\section{Recommendation 1}

mpMRI use for pre-treatment local staging of prostate cancer is a reasonable option for assessment of EPE in intermediate- 


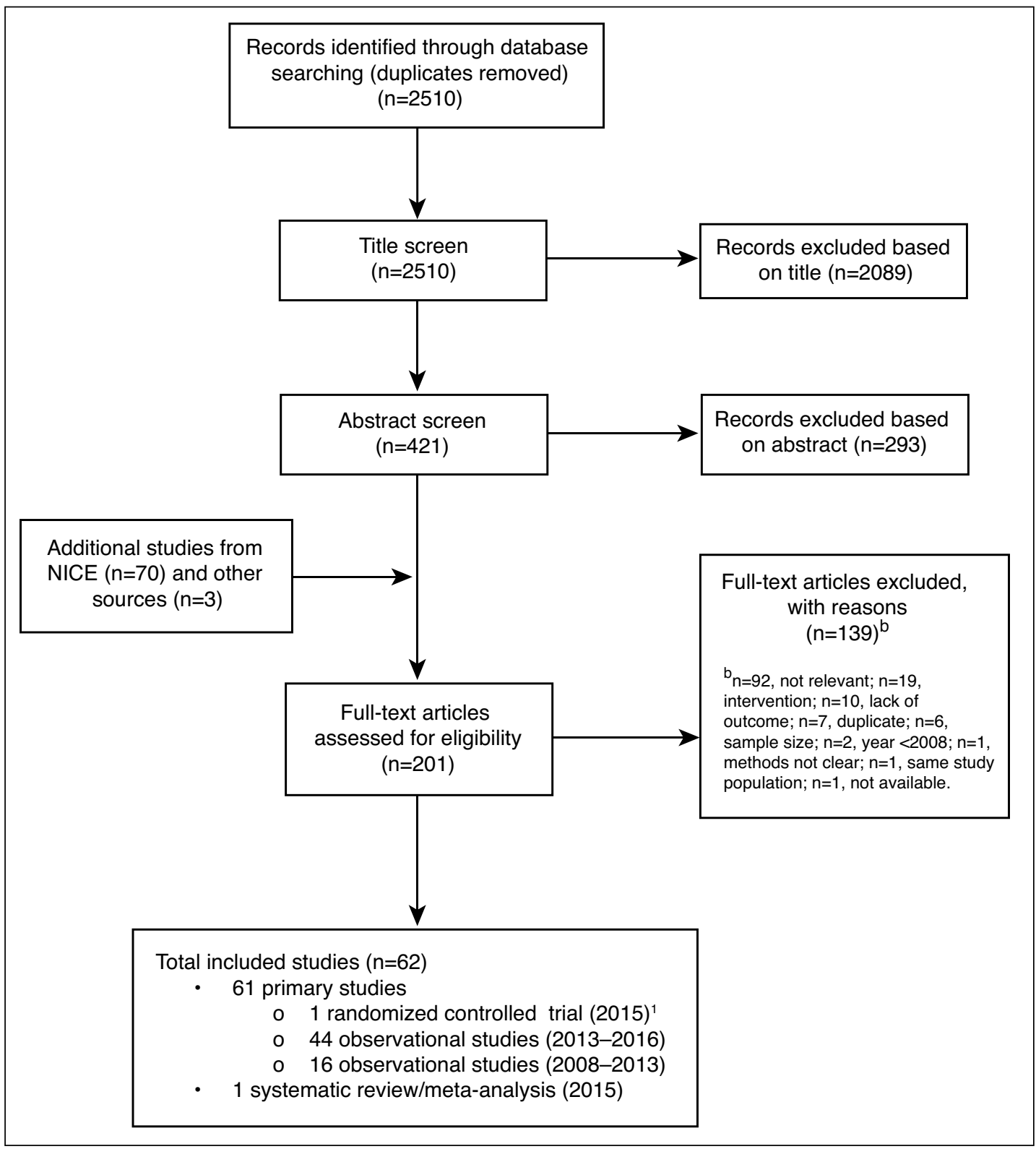

Fig. 1. Citation flow chart. ${ }^{1}$ For stage classification, the prior study ${ }^{36}$ upon which the more recent tria ${ }^{33}$ was based was also used. NICE: National Institute of Clinical and Health Excellence.

and high-risk patients being considered for radical therapy if knowledge of EPE will alter management.

\section{Key evidence}

There were $19 / 49$ (38.8\%) primary studies of MRI $\geq 1.5 \mathrm{~T}+$ $E R \pm D W I, D C E, M R S$ that considered the detection of EPE and/or SVI ${ }^{11-28}$ (Figs. 2, 3). Median sensitivities were modest and specificities were excellent, and similar to a recently published systematic review/meta-analysis ${ }^{29}$ (Table 2 ).

There were 6/61 (9.8\%) studies that reported on the outcome of change in treatment plan. ${ }^{30-35}$ All six studies were consistent in showing increased intensity of therapy as a result of MRI staging, with $<1-43 \%$ of patients experiencing increased therapy due to MRI staging. ${ }^{30-35}$ Three studies reported that MRI-informed treatment plans were correct, as shown in $63-97 \%$ of patients. ${ }^{31,32,35}$

There were 21/61 (34.4\%) studies that reported on the outcome of change in stage classification. There were 20/21 $(95.2 \%)$ studies that consistently demonstrated upstaging by MRI, ${ }^{33,36}$ and upstaging by MRI compared to routine clinical staging. $12,13,16,17,20,21,23,30,32,34,37-45$ Upstaging by MRI was correct by pathology in seven studies, with a range from $11-85 \% .^{16,17,32,34,38,41,44}$ 


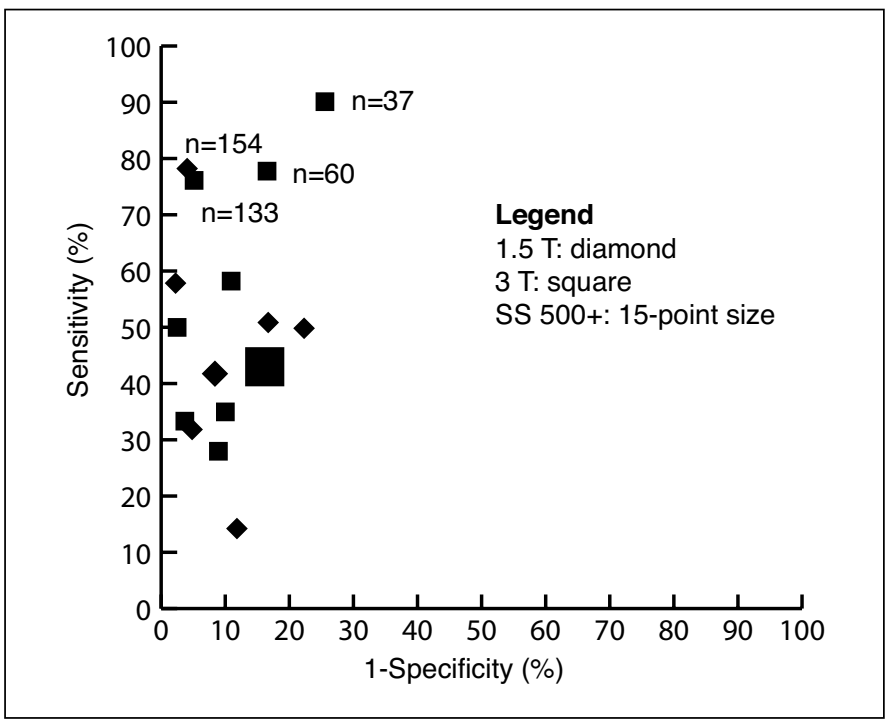

Fig. 2. Magnetic resonance imaging studies of $\geq 1.5 T+E R \pm D W I, D C E$, MRS in EPE ( $n=17)$. DCE: dynamic contrast-enhanced imaging; DWI: diffusion-weighted imaging; EPE: extraprostatic extension; ER: endorectal coil; MRS: magnetic resonance spectroscopic imaging; SS: sample size; T: Tesla.

\section{Qualifying statements}

The quality of evidence was judged to be of high risk. As a result, the above recommendation reflects a blended synthesis of evidence and expert opinion. mpMRI is best defined according to current standards. ${ }^{4}$ Furthermore, caution should be exercised when considering nerve-sparing surgery on the basis of mpMRI evaluation indicating no EPE on the side of prostate cancer.

\section{Recommendation 2}

Centres using mpMRI for local prostate cancer staging must have a quality assurance program in place to measure diagnostic performance.

\section{Key evidence and qualifying statements}

This recommendation is based on expert opinion with mpMRI best defined according to current standards. ${ }^{4}$ Quality assurance programs were not reviewed; however, use of standardized reporting has shown statistically significant improvements in sensitivity vs. non-standardized reporting. ${ }^{46}$

\section{Discussion}

Systematic review methodology combined with expert consultation informed this clinical practice guideline. Based on observational evidence, modest imaging performance was shown for MRI (1.5 T + ER and $3 \mathrm{~T} \pm \mathrm{ER}) \pm \mathrm{DWI}, \mathrm{DCE}$, $M R S$ in regards to sensitivity. Future high-quality diagnostic

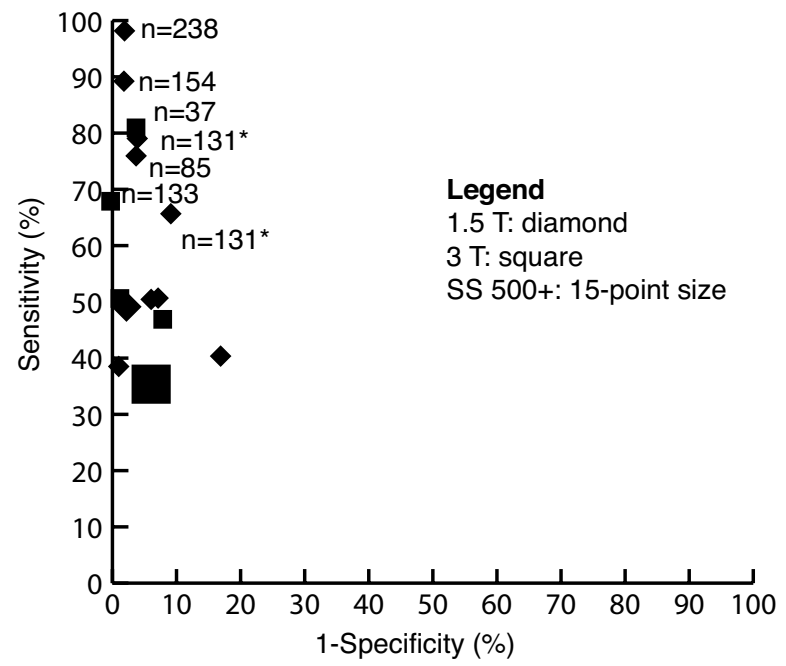

Fig. 3. Magnetic resonance imaging studies of $\geq 1.5 \mathrm{~T}+\mathrm{ER} \pm \mathrm{DWI}, \mathrm{DCE}, \mathrm{MRS}$ in SVI $(n=15)$. *Denotes data point from same study population..$^{24}$ DCE: dynamic contrast-enhanced imaging; DWI: diffusion-weighted imaging; ER: endorectal coil; MRS: magnetic resonance spectroscopic imaging; SS: sample size; SVI: seminal vesicle invasion; T: Tesla.

accuracy studies and health outcomes studies are needed to inform evidence-based recommendations.

Our systematic review of the literature is consistent with a well-conducted, recently published systematic review/ meta-analysis that reported overall sensitivity of approximately $50-60 \%$ and specificity of $>85 \%$, despite differences in methodology (e.g., years searched) and analyzed studies (e.g., ER, field strength, mpMRI). ${ }^{29}$ In our work, above average sensitivities were achieved in some studies; however, whether this was due to the addition of functional sequences or field strength was not clear owing to too few studies (Table 3). Other reports of sensitivity and specificity of MRI for local staging of prostate cancer range from 15-100\% and $67-100 \%$, respectively. ${ }^{47}$ Our synthesis of the published data showed a marked shift towards a higher minimum specificity value in the detection of EPE (74-98\% vs. 49-99\%, difference: $25 \%$ ) and a shift towards a higher minimum sensitivity value in the detection of SVI $(35-97 \%$ vs. $23-80 \%$, difference: $12 \%) .{ }^{47}$ In our work, higher performance was likely due to consideration of ER status. Among non-ER studies, 1.5 $\mathrm{T}$ had a lower sensitivity than $3 \mathrm{~T}$ (Table 2), which was also consistent with a previous detailed analysis. ${ }^{29}$

The quality assessment of ER studies on imaging performance was judged to be of high risk. Explanations surround the lack of detail reported for radiology and pathology evaluation and interpretation, and the difficulty in distinguishing between microscopic to gross EPE. ${ }^{48}$ Future studies should consider improvements in patient sampling and study design, standardized use of functional sequences, explicit pathology criteria, and blinding of both radiologists and pathologists. 


\begin{tabular}{|c|c|}
\hline Characteristic & Range or no. studies (\%) \\
\hline Age (median or mean) & $58-70$ years \\
\hline Minimum time to imaging post-biopsy & 2 weeks \\
\hline Radiologist blinding & $34(55.7)$ \\
\hline \multicolumn{2}{|l|}{ Field strength } \\
\hline $1.5 \mathrm{~T}$ & $30(49.1)$ \\
\hline $3 \mathrm{~T}$ & $30(49.1)$ \\
\hline Both & $1(1.6)$ \\
\hline \multicolumn{2}{|l|}{ Study type } \\
\hline $\mathrm{RCT}$ & $1(1.6)$ \\
\hline Retrospective & $35(57.3)$ \\
\hline Prospective & $19(31.1)$ \\
\hline Mixed & $6(9.8)$ \\
\hline \multicolumn{2}{|l|}{ PSA level (median or mean) } \\
\hline$<10 \mathrm{ng} / \mathrm{ml}$ & $41(67.2)$ \\
\hline $10-20 \mathrm{ng} / \mathrm{ml}$ & $19(31.1)$ \\
\hline$>20 \mathrm{ng} / \mathrm{ml}$ & $0(0)$ \\
\hline Not known & $1(1.6)$ \\
\hline \multicolumn{2}{|l|}{ No ER use } \\
\hline Plus body or pelvic coil & $22(36.1)$ \\
\hline Minus body or pelvic coil & $5(8.2)$ \\
\hline \multicolumn{2}{|l|}{ ER use } \\
\hline Plus body or pelvic coil & $27(44.3)$ \\
\hline Minus body or pelvic coil & $7(11.5)$ \\
\hline \multicolumn{2}{|l|}{ Imaging } \\
\hline MRI & $17(27.9)$ \\
\hline $\mathrm{MRI}+\mathrm{DWI}$ & $10(16.4)$ \\
\hline MRI + (DCE and/or MRS) & $6(9.8)$ \\
\hline $\mathrm{MRI}+\mathrm{DWI}+(\mathrm{DCE}$ and/or MRS) & $28(45.9)$ \\
\hline
\end{tabular}

DCE: dynamic contrast-enhanced imaging; DWl: diffusion-weighted imaging; ER: endorectal coil; MRI: magnetic resonance imaging; MRS: magnetic resonance spectroscopic imaging; PSA: prostate-specific antigen; RCT: randomized controlled trial.

The impact of pre-treatment local staging by MRI $\pm \mathrm{DWI}$, DCE, MRS on clinical and patient outcomes is still not clear. Although studies consistently demonstrated upstaging by imaging compared to clinical staging, this was only correct by pathology in a few studies and the magnitude was highly variable $(11 \%$ to $85 \%),{ }^{16,17,32,34,38,41,44}$ thus making any con- clusions to be drawn imprecise. There was limited information on the outcome of risk stratification category; ${ }^{30,34}$ however, the results were consistent with the trend of upstaging. Changes to treatment plan with imaging were mixed, as they included both an increase $\mathrm{e}^{30-35}$ and decrease $\mathrm{e}^{31,35}$ to therapy intensity, with a tendency towards more intense therapy across included studies. ${ }^{30-35}$ The correctness of treatment changes was under-studied. ${ }^{31,32,35}$ The relation between tumour or EPE detected on imaging to biochemical recurrence was mixed and difficult to decipher due to unclear reporting and statistical methods. ${ }^{18,37,42,43,49}$ The outcome of positive surgical margin status is a complex one, with its clinical impact increasingly scrutinized. ${ }^{50} \mathrm{~A}$ recent randomized controlled trial did not show a beneficial effect of $\mathrm{MRI}+\mathrm{DWI} \mathrm{I}^{33}$ on surgical margins. There were a number of potential limitations to the trial that diluted the ability to detect a difference in surgical margin status between groups, including: limited power; specified criteria for deciding how to modify the surgical plan based on imaging (including a wider excision at sites of tumour) was not part of the study design; limitations of the surgical technique associated with robotic surgery, including the lack of a specified surgical protocol for various types of imaging findings; and the protocol detailing communication between the radiologist and the urologist could be improved.

The quality assessment of studies informing these outcomes was judged to involve non-trivial serious risk of biases. The limitations included small study sizes, paucity of data, the lack of consistently reported outcomes across studies, and the lack of comparable analysis methods across studies. Moreover, clinical and pathology differences between stratified groups being compared need statistical consideration.

\section{Conclusion}

In summary, modest imaging performance using MRI (1.5 $\mathrm{T}+\mathrm{ER}$ and $3 \mathrm{~T} \pm \mathrm{ER}) \pm \mathrm{DWI}, \mathrm{DCE}, \mathrm{MRS}$ in the detection of EPE and SVI for patients scheduled to undergo radical prostatectomy was shown in regards to sensitivity. Our rec-

Table 2. Summary of diagnostic accuracy

\begin{tabular}{|c|c|c|c|c|c|c|c|c|}
\hline \multirow[b]{2}{*}{ Current guideline } & \multicolumn{4}{|c|}{ Sensitivity } & \multicolumn{4}{|c|}{ Specificity } \\
\hline & No. studies & Median & Min & Max & No. studies & Median & Min & Max \\
\hline \multicolumn{9}{|l|}{ ER use } \\
\hline$\geq 1.5 \mathrm{~T}$ for $\mathrm{EPE}$ & 16 & 50.0 & 14.0 & 90.0 & 16 & 91.0 & 74.0 & 98.0 \\
\hline$\geq 1.5 \mathrm{~T}$ for $\mathrm{SVI}$ & 13 & 50.0 & 34.9 & 97.0 & 15 & 96.0 & 83.1 & 100.0 \\
\hline \multicolumn{9}{|l|}{ No ER use } \\
\hline 1.5 T (tumour, EPE, SVI) & 9 & 36.2 & 0 & 81.3 & 9 & 90.3 & 65.0 & 97.7 \\
\hline $3 \mathrm{~T}$ (tumour, EPE, SVI) & 13 & 58.3 & 22.0 & 92.0 & 13 & 86.6 & 55.2 & 99.0 \\
\hline De Rooij et al (2015) & No. studies & Estimate & \multicolumn{2}{|c|}{$95 \% \mathrm{Cl}$} & No. studies & Estimate & \multicolumn{2}{|c|}{$95 \% \mathrm{Cl}$} \\
\hline EPE & 45 & 0.57 & \multicolumn{2}{|c|}{$0.49-0.64$} & 45 & 0.91 & \multicolumn{2}{|c|}{$0.88-0.93$} \\
\hline SVI & 34 & 0.58 & \multicolumn{2}{|c|}{$0.47-0.68$} & 34 & 0.96 & \multicolumn{2}{|c|}{$0.95-0.97$} \\
\hline Stage T3 & 38 & 0.61 & \multicolumn{2}{|c|}{$0.54-0.67$} & 38 & 0.88 & \multicolumn{2}{|c|}{$0.85-0.91$} \\
\hline
\end{tabular}

Cl: confidence interval; EPE: extraprostatic extension; ER: endorectal coil; SVI: seminal vesicle invasion; T: Tesla. 


\begin{tabular}{|c|c|}
\hline Characteristic & No. data or studies (\%) \\
\hline \multicolumn{2}{|l|}{ EPE } \\
\hline \multicolumn{2}{|l|}{ Field strength } \\
\hline $1.5 \mathrm{~T}$ & $9(52.9)$ \\
\hline $3 \mathrm{~T}$ & $8(47.1)$ \\
\hline \multicolumn{2}{|l|}{ Functional techniques } \\
\hline MRI & $8(47.1)$ \\
\hline MRI + DWI & $1(5.9)$ \\
\hline MRI + (DCE and/or MRS) & $0(0)$ \\
\hline $\mathrm{MRI}+\mathrm{DWI}+(\mathrm{DCE}$ and/or MRS) & $8(47.1)$ \\
\hline \multicolumn{2}{|l|}{ Studies of $>60 \%$ sensitivity } \\
\hline $1.5 \mathrm{~T}$ & $1(25.0)$ \\
\hline $3 \mathrm{~T}$ & $3(75.0)$ \\
\hline MRI & $1(25.0)$ \\
\hline MRI + DWI & $0(0)$ \\
\hline MRI + (DCE and/or MRS) & $0(0)$ \\
\hline $\mathrm{MRI}+\mathrm{DWI}+(\mathrm{DCE}$ and/or MRS) & $3(75.0)$ \\
\hline \multicolumn{2}{|l|}{ SVI } \\
\hline \multicolumn{2}{|l|}{ Field strength } \\
\hline $1.5 \mathrm{~T}$ & $10(66.7)$ \\
\hline $3 \mathrm{~T}$ & $5(33.3)$ \\
\hline \multicolumn{2}{|l|}{ Functional techniques } \\
\hline MRI & $9(60.0)$ \\
\hline MRI + DWI & $1(6.7)$ \\
\hline MRI + (DCE and/or MRS) & $0(0)$ \\
\hline $\mathrm{MRI}+\mathrm{DWI}+(\mathrm{DCE}$ and/or MRS) & $5(33.3)$ \\
\hline \multicolumn{2}{|l|}{ Studies of $>60 \%$ sensitivity } \\
\hline $1.5 \mathrm{~T}$ & $5(71.4)$ \\
\hline $3 \mathrm{~T}$ & $2(28.6)$ \\
\hline MRI & $3(42.9)$ \\
\hline $\mathrm{MRI}+\mathrm{DWI}$ & $0(0)$ \\
\hline MRI + (DCE and/or MRS) & $0(0)$ \\
\hline $\mathrm{MRI}+\mathrm{DWI}+(\mathrm{DCE}$ and/or MRS) & $4(57.1)$ \\
\hline
\end{tabular}

DCE: dynamic contrast-enhanced imaging; DWI: diffusion-weighted imaging; EPE: extraprostatic extension; ER: endorectal coil; MRI: magnetic resonance imaging; MRS: magnetic resonance spectroscopic imaging; SVl: seminal vesicle invasion; T: Tesla.

ommendations were tempered due to limited evidence. The recommendations are best used in the context of the current Cancer Care Ontario Prostate Cancer Diagnosis Pathway ${ }^{51}$ and mpMRI standards. ${ }^{4}$

Competing interests: Dr. Morash has been an Advisor for Abbvie, Astellas, AstraZeneca, Ferring, Janssen, and Sanofi. Dr. Morgan has been an Advisor for Abbvie, Accuray, Amgen, Astellas, Bayer, Janssen, and Sanofi; and has participated in clinical trials for Bayer and Janssen. Dr. Haider has been an Advisor for Bayer and has presented at numerous scientific meetings about MRI and advocates for its use in planning and staging in prostate cancer. All remaining authors report no competing personal or financial interests.

Members of the Guideline Development Group also disclosed potential conflicts of interest. One group member receives funding and is a trial co-investigator for MRI and prostate cancer and has published on MRI and radiotherapy planning. Another member receives support from an imaging company and has grant application activity in prostate imaging.
Acknowledgements: The Program in Evidence-based Care (PEBC) is a provincial initiative of Cancer Care Ontario supported by the Ontario Ministry of Health and Long-Term Care through Cancer Care Ontario. We thank The Magnetic Resonance Imaging in the Pre-Treatment Staging of Prostate Cancer Guideline Development Group* and the following individuals for their assistance in guideline development: Melissa Brouwers, Sheila McNair, Hans Messersmith. We thank Deanna Langer at Cancer Care Ontario.

*The Magnetic Resonance Imaging in the Pre-Treatment Staging of Prostate Cancer Guideline Development Group reviewed and provided expert feedback in the development of this guideline: Neil Fleshner (Princess Margaret Hospital), Glenn Bauman (London Health Sciences Centre), Joseph Chin (London Health Sciences Centre), Bobby Shayegan (St Joseph's Hospital), Rodney Breau (The Ottawa Hospital), Julian Dobranowski (St Joseph's Hospital and Cancer Care Ontario), Kartik Jhaveri (University Health Network, Mount Sinai Hospital, Women's College Hospital, and University of Toronto), Sangeet Ghai (University Health Network), and Theo van der Kwast (Toronto General Hospital).

This paper has been peer-reviewed.

\section{References}

1. Cancer Care Ontario. Ontario Cancer Statistics 2016. Toronto: Cancer Care Ontario; 2016.

2. Yacoub JH, Oto A, Miller FH. MR Imaging of the prostate. Radiol Clin North Am 2014;52:811-37. http:// dx.doi.org/10.1016/i.rcl.2014.02.010

3. Thompson J, Lawrentschuk N, Frydenberg $M$, et al. The role of magnetic resonance imaging in the diagnosis and management of prostate cancer. BJU Int 2013;112:6-20. http://dx.doi.org/10.1111/bju.12381

4. American College of Radiology. Prostate Imaging and Reporting and Data System. Available at http:// www.acr.org/ /media/ACR/Documents/PDF/QualitySafety/Resources/PIRADS/PIRADS\%20V2.pdf. Accessed March 11, 2016.

5. Shea BJ, Grimshaw JM, Wells GA, et al. Development of AMSTAR: A measurement tool to assess the methodological quality of systematic reviews. BMC Med Res Methodol 2007;7:10. http://dx.doi. org/10.1186/1471-2288-7-10

6. Whiting PF, Ruties AW, Westwood ME, et al. QUADAS-2: A revised tool for the quality assessment of diagnostic accuracy studies. Ann Intern Med 2011;155:529-36. http://dx.doi.org/10.7326/00034819-155-8-201110180-00009

7. Sterne JAC HJ, Reeves BC on behalf of the development group for ACROBATNRSI. A Cochrane Risk Of Bias Assessment Tool: for Non-Randomized Studies of Interventions (ACROBATNRSI), Version 1.0.0, 24 September 2014. Available at http://www.riskofbias.info. Accessed August 30, 2016.

8. Grades of recommendation. Grading quality of evidence and strength of recommendations. BMJ 2004;328:1490-4. http://dx.doi.org/10.1136/bmi.328.7454.1490

9. Szklo M, Nieto JF. Chapter 8: Quality Assurance and Control. Epidemiology Beyond the Basics. Gaithersburg, Maryland; Aspen Publishers, Inc.; 2000:343-404.

10. National Institute for Health and Care Excellence. Prostate cancer: Diagnosis and treatment. Available at http://www.nice.org.uk/guidance/cg175. Accessed March 11, 2016.

11. Ghafoori $M$, Alavi $M$, Shakiba $M$, et al. The value of prostate MRI with endorectal coil in detecting seminal vesicle involvement in patients with prostate cancer. Iran J Radiol 2015;12:e14556.

12. Gupta RT, Faridi KF, Singh AA, et al. Comparing 3-T multiparametric MRI and the Partin tables to predict organ-confined prostate cancer after radical prostatectomy. Urol Oncol 2014;32:1292-9. http://dx.doi. org/10.1016/i.urolonc.2014.04.017

13. Lista $\mathrm{F}$, Gimbernat $\mathrm{H}$, Caceres $\mathrm{F}$, et al. Multiparametric magnetic resonance imaging for the assessment of extracapsular invasion and other staging parameters in patients with prostate cancer candidates for radical prostatectomy. Actas Urol Esp 2014;38:290-7. http://dx.doi.org/10.1016/i.acuro.2013.11.003

14. Otto J, Thormer $G$, Seiwerts $M$, et al. Value of endorectal magnetic resonance imaging at $3 T$ for the local staging of prostate cancer. Rofo 2014;186:795-802. http://dx.doi.org/10.1055/s-0033-1356186

15. Roethke $M$, Kaufmann $S$, Kniess $M$, et al. Seminal vesicle invasion: Accuracy and analysis of infiltration patterns with high-spatial resolution T2-weighted sequences on endorectal magnetic resonance imaging. Urol Int 2014;92:294-9. http://dx.doi.org/10.1159/000353968

16. Cerantola Y, Valerio M, Kawkabani Marchini A, et al. Can $3 T$ multiparametric magnetic resonance imaging accurately detect prostate cancer extracapsular extension? Can Urol Assoc J 2013;7:E699-703. http://dx.doi.org/10.5489/cuai.245

17. Hegde JV, Chen MH, Mulkern RV, et al. Preoperative 3-Tesla multiparametric endorectal magnetic resonance imaging findings and the odds of upgrading and upstaging at radical prostatectomy in men with clinically 
Salerno et al.

localized prostate cancer. Int J Radiat Oncol Biol Phys 2013;85:e101-7. http://dx.doi.org/10.1016/i. iirobp.2012.08.032

18. Jeong IG, Lim JH, You D, et al. Incremental value of magnetic resonance imaging for clinically high-risk prostate cancer in 922 radical prostatectomies. J Uro/2013;190:2054-60. http://dx.doi.org/10.1016/i. juro.2013.06.035

19. Nepple KG, Rosevear HM, Stolpen AH, et al. Concordance of preoperative prostate endorectal MRI with subsequent prostatectomy specimen in high-risk prostate cancer patients. Urol Oncol 2013;31:601-6. http://dx.doi.org/10.1016/j.urolonc.2011.05.004

20. Porcaro $A B$, Borsato $A$, Romano $M$, et al. Accuracy of preoperative endo-rectal coil magnetic resonance imaging in detecting clinical under-staging of localized prostate cancer. World J Urol 2013;31:1245-51. http://dx.doi.org/10.1007/s00345-012-0900-7

21. Pugh TJ, Frank SJ, Achim M, et al. Endorectal magnetic resonance imaging for predicting pathologic T3 disease in Gleason score 7 prostate cancer: Implications for prostate brachytherapy. Brachytherapy 2013;12:204-9. http://dx.doi.org/10.1016/i.brachy.2011.12.013

22. Roethke MC, Lichy MP, Kniess M, et al. Accuracy of preoperative endorectal MRI in predicting extracapsular extension and influence on neurovascular bundle-sparing in radical prostatectomy. World I Urol 2013;31:1111-6. http://dx.doi.org/10.1007/s00345-012-0826-0

23. Somford DM, Hamoen EH, Futterer JJ, et al. The predictive value of endorectal 3 Tesla multiparametric magnetic resonance imaging for extraprostatic extension in patients with low-, intermediate- and high-risk prostate cancer. J Urol 2013;190:1728-34. http://dx.doi.org/10.1016/i.juro.2013.05.021

24. Soylu FN, Peng Y, Jiang Y, et al. Seminal vesicle invasion in prostate cancer: Evaluation by using multiparametric endorectal MR imaging. Radiology 2013;267:797-806. http://dx.doi.org/10.1148/ radiol.13121319

25. Turkbey B, Mani $\mathrm{H}$, Aras $\mathrm{O}$, et al. Prostate cancer: Can multiparametric MR imaging help identify patients who are candidates for active surveillance? Radiology 2013;268:144-52. http://dx.doi.org/10.1148/ radiol. 13121325

26. $\operatorname{Kim} B S, \operatorname{Kim} T H, K w o n T G$, et al. Comparison of pelvic phased-array vs. endorectal coil magnetic resonance imaging at 3 Tesla for local staging of prostate cancer. Yonsei Med J 2012;53:550-6. http://dx.doi. org/10.3349/ymi.2012.53.3.550

27. Novis MI, Baroni RH, Cerri LM, et al. Clinically low-risk prostate cancer: Evaluation with transrectal doppler ultrasound and functional magnetic resonance imaging. Clinics (Sao Paulo) 2011;66:27-34. http://dx.doi.org/10.1590/S1807-59322011000100006

28. Lee SH, Park KK, Choi KH, et al. Is endorectal coil necessary for the staging of clinically localized prostate cancer? Comparison of non-endorectal vs. endorectal MR imaging. World I Urol 2010;28:667-72. http://dx.doi.org/10.1007/s00345-010-0579-6

29. de Rooij M, Hamoen EH, Wities JA, et al. Accuracy of magnetic resonance imaging for local staging of prostate cancer: A diagnostic meta-analysis. Eur Urol 2015;70:233-45. http://dx.doi.org/10.1016/i. eururo.2015.07.029

30. Counago F, Recio M, del Cerro E, et al. Role of 3.0 T multiparametric MRI in local staging in prostate cancer and clinical implications for radiation oncology. Clin Transl Oncol 2014;16:993-9. http://dx.doi. org/10.1007/s12094-014-1186-6

31. Park $B H$, Jeon $\mathrm{HG}$, Jeong $B C$, et al. Influence of magnetic resonance imaging in the decision to preserve or resect neurovascular bundles at robotic assisted laparoscopic radical prostatectomy. J Urol 2014;192:82-8. http://dx.doi.org/10.1016/i.juro.2014.01.005

32. Panebianco V, Salkiccia $S$, Cattarino $S$, et al. Use of multiparametric MR with neurovascular bundle evaluation to optimize the oncological and functional management of patients considered for nerve-sparing radical prostatectomy. J Sex Med 2012;9:2157-66. http://dx.doi.org/10.1111/j.1743-6109.2012.02794.x

33. Rud E, Baco E, Klotz D, et al. Does preoperative magnetic resonance imaging reduce the rate of positive surgical margins at radical prostatectomy in a randomised clinical trial? Eur Urol 2015;68:487-96. http://dx.doi.org/10.1016/i.eururo.2015.02.039

34. Counago F, Del Cerro E, Diaz-Gavela AA, et al. Tumour staging using 3.0 T multiparametric MRI in prostate cancer: Impact on treatment decisions for radical radiotherapy. Springerplus 2015;4:789. http://dx.doi. org/10.1186/s40064-015-1596-0

35. McClure TD, Margolis DJ, Reiter RE, et al. Use of MR imaging to determine preservation of the neurovascular bundles at robotic-assisted laparoscopic prostatectomy. Radiology 2012;262:874-83. http://dx.doi. org/10.1148/radiol.11103504
36. Rud E, Klotz D, Rennesund K, et al. Preoperative magnetic resonance imaging for detecting uni- and bilateral extraprostatic disease in patients with prostate cancer. World J Urol 2015;33:1015-21. http://dx.doi.org/10.1007/s00345-014-1362-x

37. Armitage JN, Igali L, Ball RY, et al. Comparison of body-array MRI and Partin tables for predicting extracapsular prostate cancer. J Clin Urol 2013;6:50-4. http://dx.doi.org/10.1177/1875974212465572

38. Hole KH, Axcrona K, Lie AK, et al. Routine pelvic MRI using phased-array coil for detection of extraprostatic tumour extension: Accuracy and clinical significance. Eur Radiol 2013;23:1158-66. http://dx.doi. org/10.1007/s00330-012-2669-x

39. Johnston $R$, Wong $L M$, Warren $A$, et al. The role of 1.5 Tesla magnetic resonance imaging in staging prostate cancer. ANZ J Surg 2013;83:234-8. http://dx.doi.org/10.1111/ans. 12094

40. Renard-Penna R, Roupret $M$, Comperat E, et al. Accuracy of high resolution (1.5 Tesla) pelvic phased array magnetic resonance imaging (MRI) in staging prostate cancer in candidates for radical prostatectomy: Results from a prospective study. Urol Oncol 2013;31:448-54. http://dx.doi.org/10.1016/i. urolonc.2011.02.017

41. Tsao CW, Lin MH, Wu ST, et al. Combining prostate-specific antigen and Gleason score increases the diagnostic power of endorectal coil magnetic resonance imaging in prostate cancer pathological stage. J Chin Med Assoc 2013;76:20-4. http://dx.doi.org/10.1016/i.jma.2012.09.005

42. Ploussard $G$, Xylinas $E$, Durand $X$, et al. Magnetic resonance imaging does not improve the prediction of misclassification of prostate cancer patients eligible for active surveillance when the most stringent selection criteria are based on the saturation biopsy scheme. BJU Int 2011;108:513-7. http://dx.doi. org/10.1111/j.1464-410X.2010.09974.x

43. Park JJ, Kim CK, Park SY, et al. Prostate cancer: Role of pretreatment multiparametric 3-T MRI in predicting biochemical recurrence after radical prostatectomy. ACR Am J Roentgenol 2014;202:W459-65. http:// dx.doi.org/10.2214/AJR.13.11381

44. Brown JA, Rodin DM, Harisinghani $M$, et al. Impact of preoperative endorectal MRI stage classification on neurovascular bundle-sparing aggressiveness and the radical prostatectomy positive margin rate. Urol Oncol 2009;27:174-9. http://dx.doi.org/10.1016/i.urolonc.2008.04.009

45. Cirillo $S$, Petracchini $M$, Bona $C M$, et al. Comparison of endorectal magnetic resonance imaging, clinical prognostic factors and nomograms in the local staging of prostate cancer patients treated with radiotherapy. Tumori 2008;94:65-9.

46. Schieda N, Quon IS, Lim C, et al. Evaluation of the European Society of Urogenital Radiology (ESUR) PI-RADS scoring system for assessment of extra-prostatic extension in prostatic carcinoma. Eur J Radiol 2015;84:1843-8. http://dx.doi.org/10.1016/i.ejrad.2015.06.016

47. Zukotynski K, Haider MA. Imaging in prostate carcinoma. Hematol Oncol Clin North Am 2013;27:1163-87. http://dx.doi.org/10.1016/i.hoc.2013.08.003

48. Magi-Galluzzi C, Evans AJ, Delahunt B, et al. International Society of Urological Pathology (ISUP) Consensus Conference on Handling and Staging of Radical Prostatectomy Specimens. Working group 3: Extraprostatic extension, lymphovascular invasion and locally advanced disease. Mod Pathol 2011;24:26-38. http://dx.doi.org/10.1038/modpathol.2010.158

49. Lee HW, Seo SI, Jeon SS, et al. Can we predict real T3 stage prostate cancer in patients with clinical T3 (cT3) disease before radical prostatectomy? Yonsei Med J 2010;51:700-7. http://dx.doi.org/10.3349/ ymi.2010.51.5.700

50. Yossepowitch 0, Briganti A, Eastham JA, et al. Positive surgical margins after radical prostatectomy: A systematic review and contemporary update. Eur Urol 2014;65:303-13. http://dx.doi.org/10.1016/i. eururo.2013.07.039

51. Finelli A, Loblaw A, Toi A, et al. Prostate Cancer Treatment Pathway Version 2013.01. Available at http://www.cancercare.on.ca/common/pages/UserFile.aspx?fileld=298446. Accessed March 11, 2016.

Correspondence: Jennifer Salerno, Program in Evidence-Based Care, McMaster University, Hamilton, 0N, Canada; salernoj@mcamster.ca 


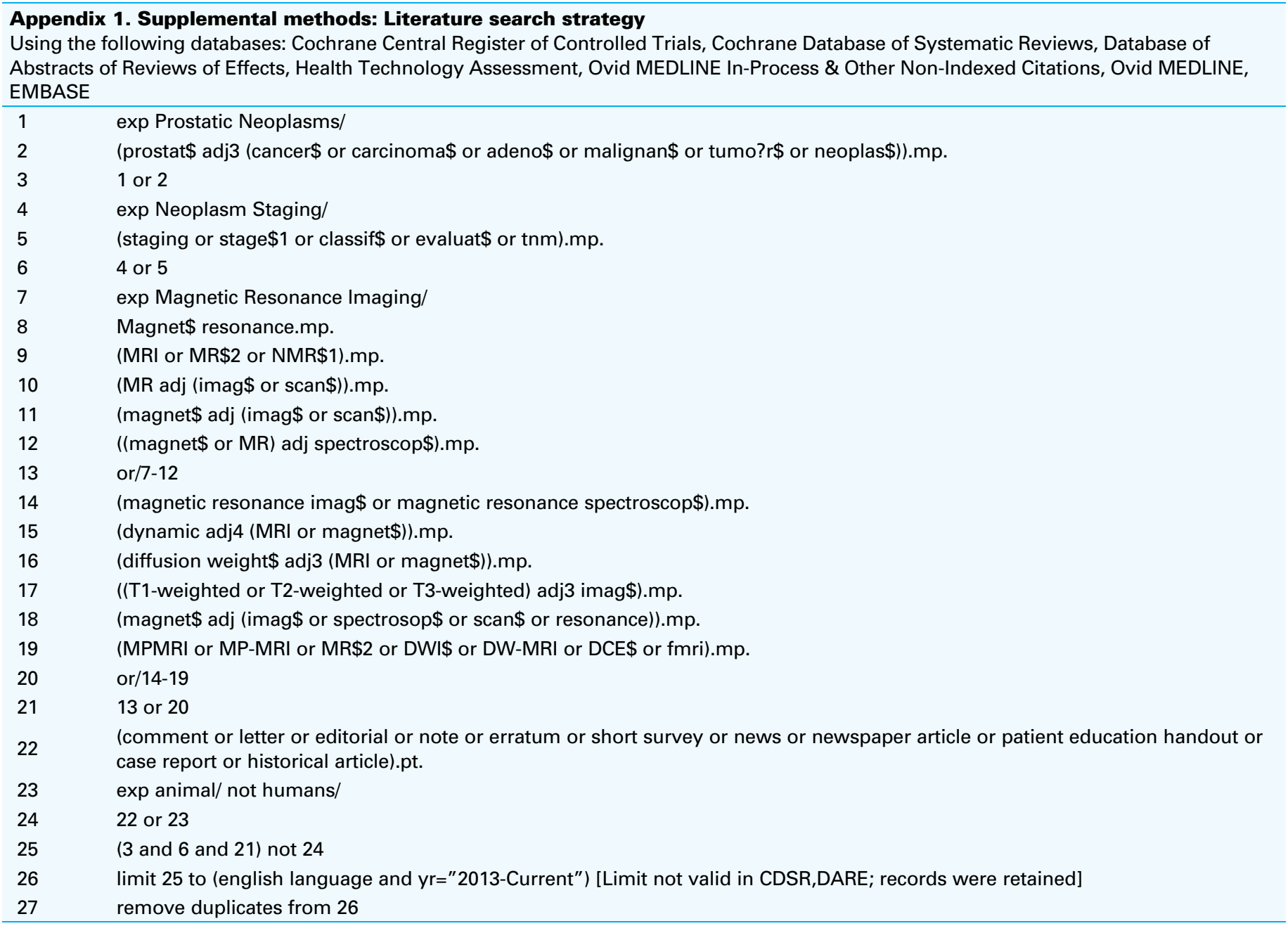

